\title{
Pertumbuhan dan Hasil Tanaman Padi (Oryza sativa L.) pada Berbagai Sistem Tanam di Kampung Desay, Distrik Prafi, Kabupaten Manokwari
}

\author{
Rice Plant Growth and Yield (Oryza sativa L.) on Various Planting Systems in Village \\ Desay District Prafi, Manokwari Regency
}

\author{
Mergono Adi Ningrat ${ }^{1 *}$, Carolina Diana Mual', Yohanis Yan Makabori ${ }^{1}$ \\ ${ }^{1}$ Program Studi Penyuluhan Pertanian Berkelanjutan, Jurusan Pertanian, Politeknik Pembangunan \\ Pertanian Manokwari \\ *Corresponding author: margono.audiningrat@gmail.com
}

\begin{abstract}
Abstrak
Padi merupakan kebutuhan primer bagi masyarakat Indonesia, karena sebagai sumber energi dan karbohidrat bagi mereka. Penurunan produksi beras dapat mempengaruhi ketersediaan pangan. Salah satu faktor yang mempengaruhi produksi padi adalah sistem tanam. Tujuan penelitian ini yaitu untuk mengetahui sistem tanam terbaik untuk pertumbuhan dan produksi tanam padi serta memberikan pengetahuan kepada petani tentang sistem tanam padi yang efektif. Penelitian dilaksanakan di Kampung Desay, Distrik Prafi, Kabupaten Manokwari. Selama 5 bulan, mulai tanggal 1 Desember 2020 - 30 April 2021. Metode yang digunakan dalam penelitian ini adalah Rancangan Acak Kelompok Lengkap (RAKL) nonfaktorial dengan 5 perlakuan dan 5 kali ulangan. Perlakuan yang diujikan ialah sistem tanam konvensional, Sistem tanam Jajar Legowo dan Sistem Tanam System of Rice Intensification. Parameter yang diamati yaitu tingkat kesuburan tanah, tinggi tanaman, jumlah anakan, jumlah malai padi dan berat gabah kering panen serta berat gabah kering giling. Terdapat pengaruh antara setiap sistem tanam terhadap tinggi tanaman, jumlah anakkan dan jumlah malai padi, namun tidak memberikan pengaruh yang nyata terhadap produksi gabah kering panen dan gabah kering giling. Sistem tanam terbaik di tunjukan oleh sistem tanam jajar legowo 4:1 dengan hasil mencapai 5,63 ton/ha gabah kering giling. Penggunaan sistem tanam jajar legowo menghasilkan produksi padi lebih tinggi sehingga dapat diterapkan untuk meningkatkan produksi padi. Sedangkan untuk pertanian berkelanjutan penggunaan sistem tanam SRI dapat digunakan karena menerapkan konsep organik dan berkelanjutan.
\end{abstract}

Kata kunci: Jajar legowo, Padi, Sistem tanam, System of rice intensification

\section{Abstract}

Rice is a primary need for Indonesians because it is a source of energy and carbohydrates for them. Decreased rice production can affect food availability. One of the factors that affect rice production is the planting system. The purpose of this research is to know the best planting system for the growth and production of rice planting and provide knowledge to farmers about an effective rice planting system. The research was conducted in Desay Village, Prafi District, Manokwari Regency. For 5 months, from December 1, 2020, to April 30, 2021. The method used in this study was a Nonfactorial Randomized Group Design (RAKL) with 5 treatments and 5 replays. The treatment tested is the conventional planting system, Jajar Legowo planting system, and System of Rice Intensification Planting System. The parameters observed are soil fertility rate, plant height, number of seedlings, number of rice malai and weight of harvest dry grain, and weight of dry milled grain. There was an effect between each planting system on plant height, number of seeds, and number of panicles, but it had no significant effect on the production of milled dry grain and harvested dry grain. The best planting system is shown by the Jajar Legowo 4: 1 cropping system with yields reaching 5.63 tons / ha of milled dry unhulled rice.. The use of the Jajar legowo planting system produces higher rice production so that it can be applied to increase 
Prosiding Seminar Nasional Pembangunan dan Pendidikan Vokasi Pertanian

Politeknik Pembangunan Pertanian Manokwari, 31 Juli 2021

e ISSN : 2774-1982

DOI : https://doi.org/10.47687/snppvp.v2i1.191

rice production. As for sustainable agriculture, the use of SRI planting system can be used because it applies the concept of organic and sustainable.

Keywords: Jajar legowo, Planting system, Rice, System of rice intensification

\section{PENDAHULUAN}

Tanaman padi merupakan tanaman budidaya yang sangat penting bagi umat manusia karena lebih dari setengah penduduk dunia tergantung pada tanaman ini sebagai sumber bahan pangan. (Utama, 2015). Padi merupakan kebutuhan primer bagi masyarakat Indonesia, karena sebagai sumber energi dan karbohidrat bagi mereka. Selain itu, padi juga merupakan tanaman yang paling penting bagi jutaan petani kecil yang ada di berbagai wilayah di Indonesia (Handono, 2013).

Menurut BPS (2018) penduduk Indonesia akan terus mengalami peningkatan, di perkirakan pada tahun 2030 penduduk Indonesia terproyeksi akan berjumlah 294,1 juta jiwa dan pada tahun 2045 akan mencapai 318,9 juta jiwa. Meningkatnya jumlah penduduk akan meningkatkan pula kebutuhan pangan. Menurut data BPS luas panen padi pada 2019 diperkirakan sebesar 10,68 juta hektar atau mengalami penurunan sebanyak 700,05 ribu hektar atau 6,15\% dibandingkan tahun 2018, hal ini mengakibatkan produksi padi mengalami penurunan. Pada tahun 2018 produksi beras setara dengan 33,94 juta ton. Sementara itu, produksi pada tahun 2019 sebesar 31,31 juta ton beras, atau mengalami penurunan sebesar 2,63 juta ton $(7,75 \%)$ dibandingkan dengan produksi tahun 2018 (BPS, 2019). Jika produksi beras terus mengalami penurunan maka akan terjadi krisis pangan.

Salah satu faktor yang mempengaruhi produksi padi adalah sistem tanam. Menurut Lita et al. (2013) pada penelitiannya menyatakan bahwa sistem tanam mempengaruhi pertumbuhan dan hasil tanaman padi. Salah satu teknologi budidaya padi yang menjadi unggulan dalam mendukung peningkatan produktivitas padi secara nasional, yaitu sistem tanam jajar legowo. Pada prinsipnya sistem tanam jajar legowo adalah meningkatkan populasi dengan cara mengatur jarak tanam. Sistem tanam ini juga memanipulasi tata letak tanaman, sehingga rumpun tanaman sebagian besar menjadi tanaman pinggir. Tanaman padi yang berada di pinggir akan mendapatkan sinar matahari yang lebih banyak, sehingga menghasilkan gabah lebih tinggi dengan kualitas yang lebih baik (Ikhwani et al., 2013). Selain sistem tanam jajar legowo sistem tanam SRI (System of Rice Intensification) juga dapat meningkatkan produksi padi. Hasil penelitian Richardson 
Prosiding Seminar Nasional Pembangunan dan Pendidikan Vokasi Pertanian

Politeknik Pembangunan Pertanian Manokwari, 31 Juli 2021

e ISSN : 2774-1982

DOI : https://doi.org/10.47687/snppvp.v2i1.191

dalam Herliana (2019) di Jawa Timur bahwa metode SRI yang diterapkan mampu menghasilkan panen rata-rata sebesar 7-8 ton/ha. Sehingga dapat meningkatkan produksi sebesar 100\% dibandingkan dengan sistem tanam biasa yang menghasilkan 3 ton/ha.

Desay merupakan salah satu desa di Distrik Prafi, Kabupaten Manokwari, mayoritas petani di Kampung Desay berprofesi sebagai petani padi. Secara umum sebagian besar petani di Kampung Desay menggunakan sistem tanam jajar legowo pola 5:1, 6:1, 7:1 dan bahkan masih ada yang menggunakan sistem konvensional, hal ini mengakibatkan produktivitas padi kurang efisien dikarenakan pola sistem tanam yang kurang efektif. Rata-rata produktivitas tanaman padi di Kampung Desay hanya mencapai 2-3 ton beras/ha atau setara dengan 3,6-5,27 ton gabah kering giling/ha.

Produksi padi dapat ditingkatkan melalui penggunaan sistem tanam yang tepat, oleh sebab itu, penelitian ini dilakukan bertujuan untuk mengetahui pengaruh sistem tanam terhadap pertumbuhan dan hasil tanaman padi.

\section{METODE}

Pelaksanaan penelitian ini berlokasi di Kampung Desay, Distrik Prafi, Kabupaten Manokwari, yang akan dilaksanakan selama 5 bulan terhitung dari tanggal 1 Desember 2020 sampai dengan 30 April 2021. Alat yang digunakan adalah hand tractor, cangkul, parang, plastik mulsa, tali, ember, kayu, penggaris, pena, meteran, timbangan, karung, paku dan palu serta kertas. Bahan yang digunakan adalah benih padi varietas Cigeulis, pupuk organik, urea, KCL, TSP dan garam.

Penelitian yang dilakukan menggunakan rancangan acak kelompok lengkap (RKAL). Faktor yang diuji adalah beberapa sistem tanam dengan 5 perlakuan dan 5 kali ulangan. Perlakuan yang diujikan, yaitu $\mathrm{P} 0=$ sistem tanam konvensional, $\mathrm{P} 1=$ sistem tanam jajar legowo 2:1, P2 = sistem tanam jajar legowo 4:1, P3 = sistem tanam SRI 30 $\mathrm{cm} \times 30 \mathrm{~cm}, \mathrm{P} 4=$ sistem tanam SRI $40 \mathrm{~cm}$ x $40 \mathrm{~cm}$.

Pengamatan dilakukan dengan mengukur tingkat kesuburan tanah sebelum dan setelah penanaman, jumlah anakkan dan tinggi tanaman pada umur 25, 45, 65 dan 85 hst, jumlah malai padi dan gabah kering panen pada saat panen serta gabah kering giling pada pasca panen. Data yang diperoleh dianalisis menggunakan analisis ragam (uji F) pada taraf 5\%. Jika hasil berbeda nyata akan dilanjutkan dengan uji beda nyata jujur (BNJ) dengan taraf $5 \%$. 
Prosiding Seminar Nasional Pembangunan dan Pendidikan Vokasi Pertanian

Politeknik Pembangunan Pertanian Manokwari, 31 Juli 2021

e ISSN : 2774-1982

DOI : https://doi.org/10.47687/snppvp.v2i1.191

\section{HASIL DAN PEMBAHASAN}

\section{Tingkat Kesuburan Tanah}

Tingkat kesuburan tanah sebelum dan setelah penanaman pada $\mathrm{pH}$ dan unsur hara $\mathrm{P}$ (fosfor) berada pada kategori yang sama. Namun kandungan unsur hara $\mathrm{N}$ (nitrogen) sebelum penanaman berada pada kategori rendah sedangkan setelah penanaman berada pada kategori sangat tinggi, hal ini dapat terjadi akibat penggunaan pupuk kimia urea, dan NPK, sehingga kandungan N menjadi sangat tinggi. Namun untuk sistem SRI kandungan unsur hara $\mathrm{N}$ sangat tinggi dapat terjadi akibat penggunaan pupuk kotoran sapi, menurut Kusmanto (2019) menyatakan bahwa kandungan unsur N dan K pada kotoran sapi lebih tinggi dari pada unsur $\mathrm{P}$, selain itu pupuk kotoran sapi juga mampu menyediakan unsur hara yang seimbang pada tanah. Hal ini juga

Tabel 1. Tingkat Kesuburan Tanah

\begin{tabular}{ccccc}
\hline \multirow{2}{*}{ Kondisi } & \multicolumn{3}{c}{ Kandungan } \\
\cline { 2 - 5 } & $\mathrm{pH}$ & $\mathrm{N}$ & $\mathrm{P}$ & $\mathrm{K}$ \\
\hline $\begin{array}{c}\text { Sebelum Penanaman } \\
\text { Setelah Penanaman }\end{array}$ & Agak masam (5-6) & Rendah & Tinggi & Sedang \\
$-\quad$ Jajar legowo & Agak masam (5-6) & Sangat Tinggi & Tinggi & Sedang \\
$-\quad$ SRI & Agak masam (5-6) & Sangat Tinggi & Tinggi & Tinggi \\
\hline
\end{tabular}

\section{Pertambahan Tinggi Tanaman}

Pada umur 25 hst, 45 hst dan 65 hst sistem tanam konvensional dan jajar legowo menunjukkan pengaruh yang tidak berbeda nyata, akan tetapi berbeda nyata dan lebih tinggi terhadap sistem tanam SRI. Selanjutnya pada saat tanaman mencapai umur 85 hst sistem tanam menunjukkan pengaruh tidak beda nyata antara sistem tanam jajar legowo dan SRI $40 \mathrm{~cm}$ x $40 \mathrm{~cm}$ namun berbeda nyata dan lebih tinggi terhadap sistem tanam SRI $30 \mathrm{~cm}$ x $30 \mathrm{~cm}$ (tabel 2), hal ini menunjukkan adanya interaksi antara setiap sistem tanam yang diujikan, perbedaan tinggi tanaman dapat terjadi akibat penggunaan pupuk yang berbeda. Pada sistem tanam konvensional dan jajar legowo menggunakan pupuk kimia sedangkan pada sistem tanam SRI menggunakan pupuk organik, ini dibuktikan dengan sistem tanam konvensional dan jajar legowo menunjukkan pengaruh tidak berbeda nyata begitu pula dengan kedua sistem tanam SRI yang di ujikan menunjukkan pengaruh tidak berbeda nyata. Menurut Supandji et al. (2019) dan Veronica et al. (2019) dalam penelitiannya menyebutkan bahwa penggunaan pupuk berpengaruh terhadap pertambahan tinggi tanaman. 
Prosiding Seminar Nasional Pembangunan dan Pendidikan Vokasi Pertanian

Politeknik Pembangunan Pertanian Manokwari, 31 Juli 2021

e ISSN : 2774-1982

DOI : https://doi.org/10.47687/snppvp.v2i1.191

\section{Pertambahan Jumlah Anakan}

Pada umur tanaman 25 hst dan 45 hst sistem tanam konvensional dan jajar legowo menunjukkan pengaruh beda nyata dan lebih tinggi dibandingkan dengan sistem tanam SRI. Namun pada saat tanaman mencapai umur 65 hst sistem tanam SRI menunjukkan pengaruh beda nyata dan lebih tinggi dibandingkan sistem tanam konvensional dan jajar legowo. Kemudian saat tanaman mencapai umur 85 hst Sistem tanam SRI $30 \mathrm{~cm}$ x $30 \mathrm{~cm}$ menunjukkan pengaruh beda nyata dan lebih tinggi dibandingkan dengan sistem tanam konvensional dan jajar legowo. Sedangkan untuk sistem tanam SRI $40 \mathrm{~cm}$ x $40 \mathrm{~cm}$ menunjukkan pengaruh beda nyata dan lebih tinggi terhadap seluruh sistem tanam yang diujikan (Tabel 3). Interaksi antara setiap sistem tanam yang diujikan dapat terjadi karena adanya perbedaan jarak tanam, sehingga mempengaruhi ruang gerak tanaman dan persaingan merebutkan unsur hara dan air dalam tanah serta cahaya matahari untuk proses fotosintesis, hal ini dapat mempengaruhi banyaknya pertambahan jumlah anakkan. Sejalan dengan penelitian Nararya et al. (2017) dan Lita et al. (2013) yang menyebutkan bahwa sistem tanam berpengaruh terhadap pertambahan jumlah anakan tanaman padi akibat perbedaan ruang gerak.

Tabel 2. Pertambahan Tinggi Tanaman

\begin{tabular}{lcccc}
\hline \multirow{2}{*}{ Perlakuan } & \multicolumn{4}{c}{ Rata-Rata } \\
\cline { 2 - 5 } & $25 \mathrm{hst}$ & $45 \mathrm{hst}$ & $65 \mathrm{hst}$ & $85 \mathrm{hst}$ \\
\hline Konvensional & $41,25 \mathrm{~b}$ & $70,8 \mathrm{~b}$ & $88,34 \mathrm{~b}$ & $107,56 \mathrm{~b}$ \\
Jajar legowo 2:1 & $41,8 \mathrm{~b}$ & $69,01 \mathrm{~b}$ & $88,38 \mathrm{~b}$ & $105,62 \mathrm{~b}$ \\
Jajar legowo 4:1 & $41,74 \mathrm{~b}$ & $71,53 \mathrm{~b}$ & $89,06 \mathrm{~b}$ & $106,5 \mathrm{~b}$ \\
SRI 30 cm x 30 cm & $30,97 \mathrm{a}$ & $53,36 \mathrm{a}$ & $67,96 \mathrm{a}$ & $91,28 \mathrm{a}$ \\
SRI 40 cm x 40cm & $29,89 \mathrm{a}$ & $54,64 \mathrm{a}$ & $71,56 \mathrm{a}$ & $98,2 \mathrm{ab}$ \\
\hline BNJ 5\% & 4,02 & 4,78 & 6,87 & 10,09 \\
\hline
\end{tabular}

Tabel 3. Pertambahan Jumlah Anakan

\begin{tabular}{lcccc}
\hline \multirow{2}{*}{ Perlakuan } & \multicolumn{4}{c}{ Rata-Rata } \\
\cline { 2 - 5 } & $25 \mathrm{hst}$ & $45 \mathrm{hst}$ & $65 \mathrm{hst}$ & $85 \mathrm{hst}$ \\
\hline Konvensional & $6,3 \mathrm{~b}$ & $23,12 \mathrm{~b}$ & $16,32 \mathrm{a}$ & $13,6 \mathrm{a}$ \\
Jajar legowo 2:1 & $5,9 \mathrm{~b}$ & $21,1 \mathrm{~b}$ & $16,5 \mathrm{a}$ & $12,36 \mathrm{a}$ \\
Jajar legowo 4:1 & $5,92 \mathrm{~b}$ & $19,9 \mathrm{~b}$ & $15,22 \mathrm{a}$ & $11,24 \mathrm{a}$ \\
SRI 30 cm x 30 cm & $1,86 \mathrm{a}$ & $14,18 \mathrm{a}$ & $23,02 \mathrm{~b}$ & $17,82 \mathrm{~b}$ \\
SRI 40 cm x 40 cm & $1,6 \mathrm{a}$ & $14,42 \mathrm{a}$ & $26,72 \mathrm{~b}$ & $25,5 \mathrm{c}$ \\
\hline BNJ 5\% & 1,92 & 4,30 & 4,15 & 4,19 \\
\hline
\end{tabular}


Prosiding Seminar Nasional Pembangunan dan Pendidikan Vokasi Pertanian

Politeknik Pembangunan Pertanian Manokwari, 31 Juli 2021

e ISSN : 2774-1982

DOI : https://doi.org/10.47687/snppvp.v2i1.191

\section{Jumlah Malai Padi}

Tabel 4 menunjukkan bahwa sistem tanam SRI $40 \mathrm{~cm}$ x $40 \mathrm{~cm}$ memiliki pengaruh beda nyata dan lebih tinggi terhadap seluruh sistem tanam lain yang diujikan. Hasil beda nyata pada malai padi dipengaruhi oleh jumlah anakan pada setiap sistem tanam, semakin banyak jumlah anakkan maka akan semakin banyak jumlah malai padi, hal ini sejalan dengan penelitian Wangiyana et al. dalam Nararya et al. (2017) yang menyatakan bahwa semakin banyak jumlah anakkan per satuan luas, maka semakin banyak jumlah malai per satuan luas dan sejalan dengan Nararya et al, (2017) yang menyatakan bahwa sistem tanam berpengaruh terhadap jumlah malai padi.

Tabel 4. Jumlah Malai Padi

\begin{tabular}{lc}
\hline \multicolumn{1}{c}{ Perlakuan } & Rata-rata Jumlah Malai Padi \\
\hline Konvensional & $15,5 \mathrm{a}$ \\
Jajar legowo 2:1 & $13,72 \mathrm{a}$ \\
Jajar legowo 4:1 & $13,52 \mathrm{a}$ \\
SRI 30 cm x 30 cm & $17,22 \mathrm{a}$ \\
SRI 40 cm x 40 cm & $24,86 \mathrm{~b}$ \\
\hline BNJ 5\% & 4,64 \\
\hline
\end{tabular}

\section{Berat Gabah Kering Panen dan Berat}

\section{Gabah Kering Giling}

Tabel di bawah menunjukkan bahwa hasil terbaik dicapai oleh jajar legowo 4:1 memberikan hasil sebesar 2.946,8 g/4 $\mathrm{m}^{2}$ atau setara dengan 7,36 ton/ha gabah kering panen, sedangkan untuk gabah kering giling memberikan hasil sebesar $2.252 \mathrm{~g} / 4 \mathrm{~m}^{2}$ atau setara dengan 5,63 ton/ha. Kemudian hasil terbanyak kedua ditunjukkan oleh jajar legowo 2:1 dengan hasil sebesar $2.706,4 \mathrm{~g} / 4 \mathrm{~m}^{2}$ atau setara dengan 6,76 ton/ha gabah kering panen, sedangkan untuk gabah kering giling memberikan hasil sebesar $2.065,2 \mathrm{~g} / 4 \mathrm{~m}^{2}$ atau setara dengan 5,16 ton/ha. Hasil ini lebih tinggi dibandingkan dengan sistem tanam konvensional dan SRI. Sistem tanam konvensional memberikan hasil sebesar 2.603,4 $\mathrm{g} / 4 \mathrm{~m}^{2}$ gabah kering panen atau setara dengan 6,5 ton/ha, sedangkan untuk gabah kering giling menunjukkan hasil sebesar $1.992,2 \mathrm{~g} / 4 \mathrm{~m}^{2}$ atau setara dengan 4,98 ton/ha. Selanjutnya untuk sistem tanam SRI menunjukkan hasil yang lebih rendah, sistem SRI 30 $\mathrm{cm}$ x $30 \mathrm{~cm}$ menunjukkan hasil yang lebih baik dari pada sistem tanam SRI $40 \mathrm{~cm}$ x 40 $\mathrm{cm}$, dengan hasil mencapai $2.345,6 \mathrm{~g} / 4 \mathrm{~m}^{2}$ atau setara dengan 5,86 ton/ha gabah kering panen dan $1.921,4 \mathrm{~g} / 4 \mathrm{~m}^{2}$ atau setara dengan 4,8 ton/ha gabah kering giling. Sedangkan sistem tanam SRI $40 \mathrm{~cm}$ x $40 \mathrm{~cm}$ menunjukkan hasil terendah dengan hasil mencapai 
Prosiding Seminar Nasional Pembangunan dan Pendidikan Vokasi Pertanian

Politeknik Pembangunan Pertanian Manokwari, 31 Juli 2021

e ISSN : 2774-1982

DOI : https://doi.org/10.47687/snppvp.v2i1.191

$2122,6 \mathrm{~g} / 4 \mathrm{~m}^{2}$ atau setara dengan 5,3 ton/ha gabah kering panen dan $1.710,4 \mathrm{~g} / 4 \mathrm{~m}^{2}$ atau setara dengan 4,27 ton/ha untuk gabah kering giling.

Tabel 5. Berat Gabah Kering Panen dan Gabah Kering Giling

\begin{tabular}{lcc}
\hline \multirow{2}{*}{\multicolumn{1}{c}{ Perlakuan }} & \multicolumn{2}{c}{ Rata-Rata } \\
\cline { 2 - 3 } & $\begin{array}{c}\text { GKP } \\
\mathrm{g} / 4 \mathrm{~m}^{2}\end{array}$ & $\begin{array}{c}\mathrm{GKG} \\
\mathrm{g} / 4 \mathrm{~m}^{2}\end{array}$ \\
\hline Konvensional & $2.603,4$ & $1.992,2$ \\
Jajar legowo 2:1 & $2.706,4$ & $2.065,2$ \\
Jajar legowo 4:1 & $2.946,8$ & $2.252,0$ \\
SRI 30 cm x 30 cm & $2.345,6$ & $1.921,4$ \\
SRI 40 cm x 40 cm & $2.122,6$ & $1.710,4$ \\
\hline BNJ 5\% & tn & tn \\
\hline
\end{tabular}

Magfiroh et al., (2017) menyatakan bahwa pola jarak tanam berpengaruh terhadap hasil tanaman padi. Kemudian Nararaya et al., (2017) menyebutkan bahwa sistem tanam jajar legowo menunjukkan hasil yang lebih tinggi dibandingkan dengan sistem tanam konvensional maupun SRI. Hal ini dapat terjadi akibat perbedaan populasi pada setiap sistem tanam, semakin banyak populasi pada sistem tanam yang digunakan maka gabah yang dihasilkan juga akan semakin banyak, hal ini sejalan dengan temuan di lapangan bahwa sistem tanam jajar legowo memiliki jumlah populasi yang lebih banyak dibandingkan sistem tanam konvensional maupun sistem tanam SRI.

\section{KESIMPULAN DAN SARAN}

Sistem tanam jajar legowo 4:1 menunjukkan hasil terbaik untuk meningkatkan produksi padi. Dengan penggunaan sistem tanam jajar legowo 4:1 dapat memberikan hasil sebesar $2.252 \mathrm{~g} / 4 \mathrm{~m}^{2}$ atau setara dengan 5,63 ton/ha gabah kering giling (GKG). kegiatan penyuluhan yang dilakukan dapat meningkatkan pengetahuan petani terhadap penggunaan sistem tanam padi yang efektif. Petani memiliki minat yang tinggi terhadap penggunaan sistem tanam jajar legowo 4:1, secara kualitatif faktor - faktor yang mempengaruhi minat petani terhadap penggunaan sistem tanam jajar legowo 4:1 adalah: 1. Penempatan demplot yang strategis; 2. Pendekatan petani secara intensif; 3. Adanya demplot terdahulu; dan 4. Petani berpikir terhadap orientasi hasil.

Penggunaan sistem tanam jajar legowo menghasilkan produksi padi lebih tinggi sehingga dapat di terapkan untuk meningkatkan produksi padi. Sedangkan untuk pertanian berkelanjutan penggunaan sistem tanam SRI dapat digunakan karena menerapkan konsep organik dan berkelanjutan. 
Prosiding Seminar Nasional Pembangunan dan Pendidikan Vokasi Pertanian

Politeknik Pembangunan Pertanian Manokwari, 31 Juli 2021

e ISSN : 2774-1982

DOI : https://doi.org/10.47687/snppvp.v2i1.191

\section{DAFTAR PUSTAKA}

Badan Pusat Statistik. (2018). Proyeksi Penduduk Indonesia 2015-2014 Hasil SUPAS 2015 (Edisi Revisi). Jakarta: PT. Gandewa Pramatya Arta.

Badan Pusat Statistik. (2019). Berita Resmi Statistik Luas Panen Dan Produksi Padi Di Indonesia 2019 No. 16/02/Th. XXIII, 4 Februari 2020.

Ikhwani, G., R.P., Eman, P., \& A.K. Makarim. (2013). Peningkatan Produktivitas Padi Melalui Penerapan Jarak Tanam Jajar Legowo. Iptek Tanaman Pangan Vol 8 No.2. 72-79.

Kusmanto. (2019). Penyuluhan Manfaat Kotoran Sapi Bagi Pertumbuhan Tanaman Padi Di Poktan Srisadono.Desa Karangrejo.Kec Kerjo.Kab Karanganyar. Tersedia: http://cybex.pertanian.go.id/mobile/artikel/71972/Penyuluhan-Manfaat-KotoranSapi-Bagi-Pertumbuhan-Tanaman-Padi--Di-Poktan-SrisadonoDesaKarangrejoKec-KerjoKab-Karanganyar/. 10 April 2021

Lita, T.N., Soekartomo, S., \& Guritno, B. (2013). Pengaruh Perbedaan Sistem Tanam Terhadap Pertumbuhan Dan Hasil Tanaman Padi (Oryza sativa L.) Di Lahan Sawah. Jurnal Produksi Tanaman, 1( 4), 361-368.

Magfiroh, N., Lapanjang, I.M., \& Made, U. (2017). Pengaruh Jarak Tanam Terhadap Pertumbuhan dan Hasil Tanaman Padi (Oryza sativa L.) Pada Pola Jarak Tanam yang Berbeda dalam Sistem Tabela. E-J. Agrotekbis, 5(2), 212-221.

Nararya, M.B.A., Santosos, M., \& Suryanto, A. (2017). Kajian Beberapa Macam Sistem Tanam dan Jumlah Bibit Per Lubang Tanam Pada Produksi Tanaman Padi Sawah (Oriza Sativa L.) var. INPARI 30. Jurnal Produksi Tanaman, 5(8), 1338-1345.

Supandji., Junaidi., \& Ion, R. (2019). Pengaruh Pupuk Urea dan Pupuk Organik Sapi Terhadap Pertumbuhan dan Produksi Tanaman Padi Varietas IR. 64 (Oryza sativa L). Jurnal Agrinika, 3(2), 107-119.

Utama, M. \& Zulman, H. (2015). Budidaya Padi Pada Lahan Marjinal. Yogyakarta: CV. ANDI OFFSET.

Veronica, N.T., Setiawan, A., \& Tyasmoro, S.Y. (2019). Respon Varietas Lokal dan Varietas Unggul Nasional Terhadap Kombinasi Pupuk Organik dan Anorganik pada Pertumbuhan dan Hasil Tanaman Padi (Oryza sativa L.). Jurnal Produksi Tanaman, 7(1), 164-172. 